\title{
NORTHERN GRASSHOPPER MOUSE
}

\author{
Photos by Robert R. Taylor
}


Photographs of a Northern Grasshopper Mouse (Onychomys leucogaster), one of a litter born to an adult shortly after its capture at Beechy in May, 1964, on the occasion of the summer field meeting of the Saskatchewan Natural History Society. Photographed in April, 1966, at Regina. 